\title{
A desigualdade racial de renda no Brasil: 1976-2006
}

Rafael Guerreiro Osório

Curso: Doutorado em Sociologia

Data da defesa: 2 de abril de 2009

Orientadora: $\operatorname{Prof}^{\mathrm{a}} \mathrm{Dr}^{\mathrm{a}}$ Lourdes Maria Bandeira

\section{Resumo}

Esta pesquisa apresenta uma análise da desigualdade racial de renda no Brasil para investigar a validade da tese de que a sua persistência se deve, preponderantemente, ao peso exacerbado da origem social nos processos de estratificação caracterizando um regime de baixa mobilidade, no qual há ainda o complemento de efeitos menores da discriminação racial. A origem social e a discriminação prejudicam os negros em suas trajetórias, a primeira mais do que a última por causa da associação entre raça e estratificação legada pelo passado escravista. Porém, o complemento proporcionado pela discriminação é fundamental para gerar a persistência, pois, na sua ausência, o regime de mobilidade induziria uma equalização racial lenta.

A análise é conduzida mediante técnicas estatísticas a partir de bases de dados que contêm as respostas aos questionários aplicados de 1976 a 2006 pela Pesquisa Nacional por Amostra de 
Domicílios (PNAD), realizada pelo Instituto Brasileiro de Geografia e Estatística (IBGE), com ênfase nos dados de 1976, 1986, 1996 e 2006. A desigualdade racial de renda considerada é a de renda domiciliar per capita entre brancos e negros, grupo formado pela agregação de pretos e pardos.

A tese foi quebrada em seis hipóteses que guiaram a pesquisa e a análise dos dados. Todas as seis são compatíveis com os dados, corroborando a tese. Mostra-se progressivamente que: i) existe desigualdade racial de renda domiciliar per capita no Brasil; ii) essa desigualdade é persistente de 1976 a 2006, seu nível é relativamente constante; iii) os dois grupos raciais têm regimes de baixa mobilidade, o que denota a importância da origem social nesses processos; iv) a principal fonte da desigualdade racial de renda é a diferença no nível da renda do trabalho de negros e brancos; v) a diferença no nível da renda do trabalho deve-se, preponderantemente, às desigualdades educacionais entre negros e brancos; vi) as desigualdades educacionais entre os grupos raciais são, em larga escala, determinadas pela origem social.

Palavras chave: desigualdade racial; mobilidade social; discriminação racial; estratificação social; distribuição de renda. 